\title{
Adolfo Sánchez Vázquez y el marxismo francfortiano
}

Stefan Gandler

$\mathrm{V}$ amos a tratar de confrontar filosóficamente a Adolfo Sánchez Vázquez con algunos conceptos centrales de la tradición de la teoría crítica. En relación con la última, vamos a adentrarnos en el pensamiento de uno de los seguidores, alumnos y colaboradores más importantes de Horkheimer, Adorno, Marcuse, Benjamin y Neumann, muy probablemente el más relevante entre los hoy en día vivos: Alfred Schmidt. ${ }^{1}$

Para Adolfo Sánchez Vázquez, como también para los autores de la teoría crítica, una de las cuestiones filosóficas fundamentales es la relación entre el idealismo y el materialismo (premarxiano) y la del carácter, al fin y al cabo materialista, de una interpretación de Marx orientada a la praxis. ${ }^{2}$ Estas problemáticas teóricas tenían y tienen consecuencias de largo alcance por cuanto dan origen a que una filosofía y una teoría marxista crítica hayan de atreverse a caminar sobre la cuerda floja permanentemente, una cuerda floja conceptual a la que ésta tendencia filosófica debe, en buena medida, su encanto y su importancia, pero que, a la vez, es un motivo filosófico interno para que esta corriente teórica no goce de muchas simpatías en el actual contexto político.

Pensadores o actores burgueses se complacían en lanzar a esa corriente la sospecha de que estaba aliada a oscuras fuerzas de la Unión Soviética, reproche

${ }^{1}$ N. del E. Alfred Schmidt murió el 28 de agosto de 2012, fecha posterior a la recepción del texto de Stefan Gandler.

${ }^{2}$ Compárese: "El hecho de que el punto de partida del materialismo dialéctico sea de carácter específicamente epistemológico, se debe a que Marx y Engels aceptan la crítica que Hegel hace a Kant sin poder aceptar al mismo tiempo su base especulativa. Con Hegel afirman la posibilidad de conocer la esencia de los fenómenos, con Kant ( $\sin$ referirse ciertamente a la Crítica de la razón pura) insisten en la no-identidad de forma y materia, sujeto y objeto del conocimiento. Se llega así -si bien sin expresarlo abiertamente- a una reedición materialista de la problemática de la constitución" (Alfred Schmidt, "Einleitung", en A. Schmidt, ed., Beiträge zur marxistischen Erkenntnistheorie. Fráncfort del Meno, Suhrkamp, 1969, pp. 10-11). 
que todavía encuentra adeptos después del fin del experimento del socialismo real. Entre los teóricos o activistas marxistas, por el contrario, esa corriente teórica, conocida como marxismo occidental, despertó siempre la sospecha de que podía contener un reblandecimiento "burgués" de la crítica marxista a las relaciones capitalistas de producción y de la sociedad burguesa reinantes. Con el fin de la Unión Soviética, también han desaparecido de la faz de la Tierra la mayoría de los marxistas dogmáticos. Los antiguos marxistas dogmáticos se desatan ahora, en su mayoría, en improperios, recordando de repente que siempre fueron buenos demócratas burgueses e incansables anticomunistas contra toda persistencia de una formación teórica marxista, y afirman con alivio que, por lo menos, algo se ha mantenido estable en su pensamiento: el rechazo a una interpretación no dogmática de Marx.

Esta primera manera de evitar una autorreflexión sobre las propias debilidades teóricas en un momento anterior (al proyectar los propios defectos de la interpretación de Marx sobre otros que siempre fueron sospechosos), se complementa con una segunda. Algunos marxistas antiguamente dogmáticos, están ahora convencidos de haber sido siempre marxistas críticos, no dogmáticos. Mediante esta reconstrucción de su propia historia teórica evitan, a su manera, la autocrítica pendiente.

El filósofo de Fráncfort, Alfred Schmidt, es uno de los teóricos que trabajaba, ya mucho antes del fin de la Unión Soviética, en una interpretación de Marx autónoma y no dogmática frente a sus filósofos de Estado y, después de la terminación del experimento del socialismo real, no quiere que caiga en el olvido su propia producción filosófica de aquella época. ${ }^{3}$ En vista de que Alfred Schmidt ha hecho aportaciones decisivas a la discusión filosófica no dogmática del marxismo, sobre todo en el terreno de la teoría del conocimiento, resulta provechoso contrastar algunas de sus reflexiones con la filosofía de Sánchez Vázquez.

En lo que concierne a la relación entre praxis y conocimiento, Sánchez Vázquez desarrolla en su Filosofía de la praxis: "la intervención de la praxis en el proceso de conocimiento lleva a superar la antítesis entre idealismo y materialismo", es decir, la antítesis "entre la concepción del conocimiento como conocimiento de objetos producidos o creados por la conciencia y la concepción que ve en él una mera reproducción ideal de objetos en sí”. ${ }^{4}$ Es

${ }^{3}$ Alfred Schmidt manifestó hace unos años que seguía defendiendo lo afirmado en su libro El concepto de naturaleza en Marx. Aludiendo evidentemente al trato que dio Max Horkheimer a sus propios escritos anteriores después de haber regresado a Fráncfort en 1947 del exilio en Estados Unidos, Schmidt dijo que él no encerraría en el sótano sus anteriores escritos (comunicación personal, $c$. 1993).

${ }^{4}$ Adolfo Sánchez Vázquez, Filosofía de la praxis. 2a. ed., corregida y aumentada. México, Grijalbo, 1980, p. 153. 
preciso rebasar ambas posiciones: no se puede perseverar ni en una teoría idealista del conocimiento ni en "una teoría realista como la del materialismo tradicional, que no es sino un desenvolvimiento del punto de vista del realismo ingenuo". 5

Sánchez Vázquez señala en este lugar que distintos intérpretes de Marx extraen diferentes conclusiones de la introducción del concepto de praxis al problema del conocimiento, mencionando al respecto tres posiciones:

1. "[...] el hecho de que la praxis sea un factor en nuestro conocimiento no significa que no conozcamos cosas en sí".

2. "[...] la aceptación de este papel decisivo de la praxis entraña que no conocemos lo que las cosas son en sí mismas, al margen de su relación con el hombre, sino cosas humanizadas por la praxis e integradas, gracias a ella, en un mundo humano (punto de vista de Gramsci)".

3. "[...] se sostiene acertadamente que sin la praxis como creación de la realidad humana-social no es posible el conocimiento de la realidad misma (posición de K. Kosík)" ${ }^{6}$

La diferencia entre las posiciones 2 y 3 no es inmediatamente obvia. A partir del conjunto de la Filosofía de la praxis es posible esbozar a grandes rasgos la diferencia entre las tres, así como la valoración aportada por Sánchez Vázquez. Mientras que la posición 1 reconoce, aunque subestima, la relevancia epistemológica de la praxis humana, la posición 2 va en sentido opuesto y da a la praxis humana una importancia tal que, fuera de su influencia, ya no existe ninguna realidad. ${ }^{7}$ La tercera posición aprecia, al igual que la segunda, la relevancia epistemológica de la praxis como insustituible, pero, contrariamente a la segunda posición, no hace de esto una afirmación ontológica y, por tanto, tiene en común con la primera posición el reconocimiento de la primacía del objeto.

Alfred Schmidt sostiene, al igual que su contemporáneo hispano-mexicano, la tercera de las tres posiciones mencionadas. Mientras que Sánchez Vázquez reconoce la primacía de la materia, pero insiste en que la realidad exterior sólo es reconocible para los seres humanos en tanto ellos ya hayan entrado en una relación práctica con ella, Alfred Schmidt formula una idea similar pero en tres variantes diferentes. El ser material, que existe, sin duda, independientemente

${ }^{5}$ Idem.

${ }^{6}$ Ibid., pp. 153-154.

${ }^{7}$ Esta postura de Gramsci es caracterizada, en otro lugar, por Sánchez Vázquez con las palabras del propio Gramsci como "inmanentismo absoluto", "historicismo absoluto" y "humanismo" (ibid., p. 56). 
de los sujetos humanos, sólo "adquiere significado" en una primera formulación, ontológica si se quiere, después de haber pasado por la praxis humana:

Por cierto que el ser material, como infinidad extensiva e intensiva, precede a toda figura de la praxis histórica. Pero en cuanto adquiere significado para los hombres, ya no es más que aquel ser material abstracto que debe ser puesto como un primero en sentido genético por una teoría materialista, sino que es un elemento derivado, algo apropiado mediante el trabajo social. ${ }^{8}$

En una segunda formulación, el autor de Frankfurt dice, además, que la existencia de la objetividad material natural, precursora de la praxis humana, sólo llega a ser "pronunciable" cuando se ha vuelto objeto de la praxis humana, por lo menos parcialmente:

El sujeto social, a través de cuyo filtro pasa toda la objetividad, es y sigue siendo componente suyo. Por mucho que el hombre, "cosa natural con conciencia propia", traspase la inmediatez de la "materia natural" encontrada al llegar en cada caso, al transformarla anticipando idealmente sus metas, no se rompe por ello la cohesión natural. Frente a ella (también en esto sigue Marx la "lógica" de Hegel) el quehacer orientado a un fin sólo puede imponerse si se engrana con astucia en el desarrollo de las leyes propias de la materia. El hecho de que existan "de por sí", independientes de toda praxis (y de sus implicaciones teóricas) es, desde luego, pronunciable sólo en la medida en que el mundo objetivo se haya convertido en uno "para nosotros". ${ }^{9}$

Esta segunda formulación capta la problemática en el plano filosófico-lingüístico. En ella, al igual que en la primera, está englobada la problemática más amplia de que una materialidad exterior al campo de influencia inmediato de la praxis humana sólo puede ser aprehendido por los sujetos en contraposición a

${ }^{8}$ A. Schmidt, El concepto de naturaleza en Marx. Trad. de J. M. T. Ferrari de Prieto y E. Prieto. 4a. ed. México, Siglo XXI, 1983, p. 222). Schmidt igualmente formula en otro lugar: "Como todo materialismo, el materialismo dialéctico reconoce también que las leyes y formas de movimiento de la naturaleza externa existen independientemente y fuera de cualquier conciencia. Este en-sí sólo resulta empero relevante en la medida en que se vuelve un para-nosotros, es decir, en cuanto la naturaleza se incluye en los fines humanos sociales" (ibid., p. 54. Las cursivas son mías).

${ }^{9}$ A. Schmidt, "Praxis", en H. Krings, H. M. Baumgartner y C. Wild, eds., Handbuch Philosophischer Grundbegriffe. Múnich, Kösel, 1973, t. 4, p. 1117 . Las cursivas son mías. 
la materia ya formada por la praxis. Esto llega hasta el punto de que el mismo término de 'lo intocado' de la naturaleza externa sólo puede ser creado por seres humanos que ya practican un dominio masivo sobre la naturaleza y, por tanto, saben lo que significa no dejar precisamente intacta la naturaleza, sino 'tocarla' con violencia. "Aun los objetos que todavía no han caído en el ámbito de la intervención humana dependen del hombre en la medida de que su ser intocado sólo se puede formular con relación al ser humano". ${ }^{10}$

Schmidt da una razón de por qué en este contexto no recurre a la relación cognoscitiva entre sujeto y objeto, a la que Sánchez Vázquez se refiere ante todo. "La cuestión de la unidad y la diferencia entre sujeto y objeto pierde su carácter supratemporal, limitadamente 'cognoscitivo'; demuestra ser la unidad y diferencia (determinada en forma distinta en cada caso) de historia y naturaleza. Ambas se penetran entre sí, desde luego sin volverse idénticas; siempre tienen los hombres la experiencia de una 'naturaleza histórica' y de una 'historia natural'". ${ }^{11}$

En otro pasaje, el filósofo inserto en la tradición de la Teoría Crítica de la Escuela de Frankfurt, señala que la añoranza romántica por la 'bella naturaleza de Dios' se forma históricamente en el preciso momento en que en determinada nación o región el desarrollo industrial, con el consiguiente dominio sobre la naturaleza por medio de la gran maquinaria, ha alcanzado cierta extensión, al igual que la destrucción de la naturaleza. Así fue como a unos señores burgueses de las ciudades industriales inglesas de los albores del capitalismo, vestidos con camisa a cuadros, se les ocurrió la idea de escalar las cimas de los Alpes, anhelo que declararon irresistible. ${ }^{12}$ La población nativa sólo pudo

${ }^{10}$ Idem. En el plano lingüístico se observa esta circunstancia ante todo también en la creación literaria. En ella, la naturaleza virgen es descubierta en el instante mismo en que su conquista definitiva aparece en el orden del día. Así, el poeta inglés Percy Bysshe Shelley describe en 1816 el Mont Blanc, en su poema del mismo nombre, como "Remote, serene, and inaccessible" después de que, en los veinte años transcurridos desde la primera ascensión en 1786 , su cima fuera pisada otras cinco veces por grupos de escaladores (P. B. Shelley, "Mont Blanc, Lines Written in the Vale of Chamouni", en M. W. Shelley, ed., History of a Six Weeks' Tour. Ed. facsimilar. Oxford, Woodstock, 1989 [Original: Londres, Hookham, 1817], línea 97).

${ }^{11}$ A. Schmidt, "Praxis", en op. cit., p. 1117 . Schmidt se refiere aquí a K. Marx y F. Engels, Die Deutsche Ideologie. Berlín, 1953, p. 43.

${ }^{12}$ Las primeras ascensiones a altas montañas, sobre todo de Los Alpes, son un buen ejemplo de la relación entre naturaleza externa virgen o materialidad, por un lado, y subjetividad o praxis, por el otro. La idea de una naturaleza virgen tiene, a partir de determinado instante de su tangibilidad potencial, imaginable, una increíble fuerza de atracción y, así, la intangibilidad, que desde el principio de su imaginación está vinculada a la tangibilidad potencial, se convierte en algo ya tocado. La primera alta montaña en ser escalada en Europa según el registro histórico, es el Mont Blanc, el más 
asombrarse de semejante trajín. Su distancia de la naturaleza exterior al ser humano no era tan grande como para hacerla objeto de apetencia o percibirla siquiera como tal.

En una tercera formulación -del tipo de la filosofía de la conciencia- el mundo material, en su forma de movimiento regular, no necesitado del sujeto en sí, sólo es 'reconocible' o 'asegurable' mentalmente en cuanto que ya haya sido objeto de la praxis humana. Esta tercera formulación, evidentemente, se aproxima a la de Adolfo Sánchez Vázquez: "Lo dialéctico del materialismo marxista no consiste en que se niegue a la materia toda legalidad y movimiento propio sino en la comprensión de que sólo a través de la praxis mediadora pueden los hombres reconocer y emplear teléticamente las formas de movimiento de la materia". ${ }^{13}$

En otro pasaje, Alfred Schmidt formula una idea similar al describir la relación del materialismo en general con el materialismo dialéctico: "El materialismo en general significa: las leyes de la naturaleza subsisten independientemente y fuera de la conciencia y la voluntad de los hombres. El materialismo dialéctico significa: los hombres sólo pueden asegurarse de estas legalidades a través de las formas de su proceso laboral". ${ }^{14}$

En el momento de la actividad productiva, los seres humanos chocan con las líneas fronterizas de la transformabilidad de la materia y, así, reconocen su regularidad. Sólo reconociendo esa regularidad pueden, a su vez, modificar las barreras de la naturaleza donde su contenido objetivo lo haga posible. El doble movimiento de la praxis a la teoría y de la teoría a la praxis, señalado por Adolfo Sánchez Vázquez, también es visible en las consideraciones de Alfred Schmidt. Con referencia a las reflexiones de Marx y Hegel sobre los "contenidos teléticos perseguidos en el trabajo", resaltando la praxis productiva, Schmidt plantea esta idea: "El saber anticipador presupone igualmente una conducta

alto del continente. Esta primera gran ascensión alpina tiene lugar tres años antes de la Revolución francesa. No es sólo el desarrollo industrial, sino además el ideológico, el que provoca y hace posible tal anhelo por alcanzar lo aparentemente inalcanzable de la naturaleza externa.

Los primeros en ascender al Mont Blanc, el guía Jaques Balmat y el doctor en medicina Michel Paccard, si bien eran habitantes de Chamonix, acudieron al llamado del especialista en ciencias naturales, Horace Bénédict de Saussure, quien había ofrecido un premio por la ascensión al Mont Blanc. Un año después, el propio De Saussure alcanzó la cima con dieciocho cargadores en el curso de varios días. Equipado con diversos instrumentos de medición, una mesa y una silla, pasó allí cuatro horas y media, y practicó, entre otros, unos ensayos higrométricos como los del punto de ebullición del agua y tomó nota de los efectos que causaba en su propio cuerpo la elevada altura. (Cf. H. B. de Saussure, Premières ascensions au Mont Blanc: 1774-1787. París, F. Maspero, 1979).

${ }^{13}$ A. Schmidt, El concepto de naturaleza en Marx, p. 111. Las cursivas son mías.

${ }^{14}$ Ibid., p. 112. Las cursivas son mías. 
práctica ya cumplida, de la cual surge, como también constituye a su vez el presupuesto de toda conducta". ${ }^{15}$

Ahora bien, para los dos autores aquí consultados, es de gran importancia insistir en que esta dependencia recíproca entre praxis y conocimiento no pone a ambas lisa y llanamente en el mismo nivel. La relación de mutua dependencia no lleva a una suspensión de la primacía de la materia frente al sujeto y su capacidad de conocimiento y decisión. Pero, a la vez, en el materialismo marxiano esta "prioridad de la naturaleza externa" no es estática sino mediada: ${ }^{16}$ "La naturaleza es para Marx un momento de la praxis humana y al mismo tiempo la totalidad de lo que existe". ${ }^{17}$

Estas reflexiones son mucho más que una sutileza filosófica. El camino sobre la cuerda floja que una filosofía de la praxis ha de realizar, según dijimos al inicio, es parafraseado por Alfred Schmidt de la siguiente forma:

Estas consideraciones son menos triviales de lo que parece; pues si el concepto de praxis se tensa en exceso a la manera de Fichte (como en la época temprana de Lukács, que transforma el materialismo histórico en un franco idealismo "generador" con ropaje sociológico), pierde su filo para volverse concepto de mera contemplación. Pues la "actividad pura y absoluta que no sea sino actividad" va a parar a fin de cuentas a la "ilusión del 'pensamiento puro'". ${ }^{18}$

Sobre esta argumentación se puede comentar lo siguiente: esta ilusión del pensamiento puro y la actividad pura conduce en la praxis política a la presunción de que los procesos ideales determinan los procesos materiales. Para juzgar una política determinada, en esta lógica sólo se examinan las estrategias de argumentación de los agentes y de sus seguidores en busca de concordancia interna del razonamiento (por ejemplo, en su argumentación moral), en lugar de preguntarse por los motivos reales de esa política. En consecuencia, los efectos de esa política no son considerados y valorados como tales, sino siempre respecto a si fueron deseados o no.

En la discusión teórica del marxismo, a la vez, el concepto de praxis es indispensable para poder hacer frente a las tendencias objetivistas tanto de

${ }^{15}$ Ibid., pp. 114-115.

16 "Como en el caso de Feuerbach, también Marx habla de la 'prioridad de la naturaleza externa'. Sin embargo, formula una reserva crítica: que toda prioridad sólo puede serlo dentro de la mediación" (ibid., p. 22.). Alfred Schmidt cita aquí a Marx según K. Marx y F. Engels, op. cit., p. 44.

${ }^{17}$ A. Schmidt, El concepto de naturaleza en Marx, p. 23.

18 A. Schmidt, "Praxis", en op. cit., p. 1117. Schmidt cita aquí según K. Marx y F. Engels, op. cit., pp. 452-453. 
la izquierda reformista como de la stalinista. A pesar de las considerables diferencias teóricas, un importante paralelismo entre la izquierda revisionista y la dogmática consiste en que ambas suelen (o solían) concebir la transición al socialismo como un proceso ineludible. La posición reformista parte de que esa transición se realizará mediante un tránsito, lo más suave posible, por el capitalismo y una paulatina transformación (sólo acelerable mediante reformas) de las estructuras capitalistas en socialistas. Los ortodoxos, en cambio, invocan la concepción de que habrá de llegarse a una ruptura radical en determinado momento. A pesar de esa diferencia, tienen algo en común: ambas tendencias no temen a nada tanto como a la rebelión espontánea de los oprimidos y explotados más allá de las estructuras de partido y organización que les están dadas.

Pero otorgar a la praxis en la teoría un punto tan central como lo hacen Adolfo Sánchez Vázquez y Alfred Schmidt en sus respectivas indagaciones filosóficas, pone radicalmente en duda estas concepciones objetivistas de política e historia. En el concepto de praxis, fundamental para la teoría marxista, está contenido un factor de rebeldía contra todos aquellos que, desde el escritorio, desde la central del Partido o desde la patria del proletariado quieren dirigir las actividades de los rebeldes de todos los países. Puesto que el concepto de praxis ya contiene en sí la mediación de teoría y actividad y, hablando más en general, de sujeto y objeto, y puesto que la separación tajante de ambas (contenida en la concepción de conducir a las masas a través del Partido) lleva a un completo absurdo con base en reflexiones teóricas, este concepto se resiste al autoritarismo tanto de reformistas como de ortodoxos. Puesto que ambas corrientes, frente a la espontánea rebeldía de las masas, gustan de presentar el argumento de que éstas carecen de conocimientos teóricos y de preparación, a fin de volver a acaudillarlas, la filosofía de la praxis, que en un terreno altamente teórico alega a favor de la praxis, es un aguijón no tan fácil de sacar. Se enfrenta a los cuadros (que pretenden ser superiores a las masas en lo teórico) en su terreno reivindicado como propio. Pero esto no es, en modo alguno, tomar partido sin más ni más por la actuación espontánea no reflexionada, por el practicismo y contra la teoría. Tanto a Adolfo Sánchez Vázquez como a Alfred Schmidt, les interesa más bien demostrar en sus interpretaciones de Marx que el teoricismo (y la terca obstinación en la propia preparación teórica frente a aquellos que no la tienen formalmente) no está necesariamente más próximo al conocimiento teórico que la praxis en el pleno sentido de la palabra. ${ }^{19}$ Así, debe entenderse que Schmidt, al igual que

${ }^{19}$ Bertolt Brecht expresa una idea parecida cuando en los Diálogos de refugiados, el personaje del intelectual confiesa al personaje del proletario: "[...] pienso siempre en el filósofo Hegel. He sacado algunas de sus obras de la biblioteca para no irle a usted 
Sánchez Vázquez, insista en que la "praxis histórica [...] es en sí 'más teórica' que la teoría". ${ }^{20}$

Estas referencias a la izquierda reformista y a la ortodoxa podrán parecer demasiado anacrónicas a más de una lectora o lector. Realmente lo son a primera vista, dado que la izquierda 'ortodoxa' ha quedado en nada a partir de 1989 y la izquierda reformista se ha transformado paralelamente en un andamiaje político que, si bien tiene bajo su control varios gobiernos de Europa -y últimamente de América Latina-, en el mejor de los casos, ya no tiene en común con el propio proyecto original más que el nombre. Mientras al principio del siglo, y en parte incluso en los primeros años posteriores a la Segunda Guerra Mundial, los partidos socialdemócratas de Europa conceptualizaron la necesidad y la posibilidad de una transición al socialismo -y reformismo no significaba para ellos poner en duda esa meta sino sólo el camino hacia ella frente a la posición marxiana clásica-, hoy las cosas son muy distintas. Cuando llegan a impulsarse reformas, ya no es como alternativa a la revolución socialista, sino como el medio más seguro de garantizar la persistencia del capitalismo, al tratar de mitigar las consecuencias de sus más absurdas contradicciones con medidas que bien podrían provenir de conservadores ilustrados. ${ }^{21}$

A pesar de todo, estas reflexiones siguen siendo de gran importancia cuando se nos plantea hoy, con una urgencia no disminuida, el problema de la relación entre teoría y actividad, de subjetividad y relaciones objetivas, de cuadros y base del Partido. Hasta hoy sigue siendo válido que acentuar la significación de la praxis no significa tomar partido lisa y llanamente por la subjetividad frente a la importancia de las relaciones objetivas. En el concepto crítico filosófico de la praxis, interesa más bien concebir la relación dialéctica entre estas dos instancias, que solamente se puede contraponer de manera tan sencilla a nivel terminológico, y entender su importancia. Así, debe seguirse la reflexión de Alfred Schmidt cuando señala que el objetivismo

a la zaga, filosóficamente hablando" (B. Brecht, Diálogos de refugiados. Trad. de Juan del Solar. Madrid, Alianza, 1994, t. 7, p. 88. Las cursivas son mías). De todos modos, esto sólo debe entenderse negativamente, es decir, como crítica irónica al teoricismo y no como banal culto al proletario. Como alusión al simultáneo desdén por las capacidades conceptuales de la clase obrera, chapuceramente elogiada, que halla su expresión en la sustitución de los clásicos por los libros de texto por parte del Partido Comunista, el personaje del proletario agrega poco después, volviendo a referirse a Hegel: "Nos dieron extractos de sus obras. En él, como en los cangrejos, hay que atenerse a los extractos" (ibid., p. 91).

${ }^{20}$ A. Schmidt, El concepto de naturaleza en Marx, p. 223.

${ }^{21}$ Esta no es una suposición maliciosa, sino sólo un resumen de los más recientes programas de partido y gobierno de la socialdemocracia europea. Apenas habría hoy un socialdemócrata que siguiera poniendo en tela de juicio la interpretación de estos programas como procapitalistas. 
liso y llano y el simple subjetivismo de ninguna manera deben identificarse como contrarios inequívocos, sino que, en determinadas ideologías o formas de acción política, ambos suelen coexistir. Respecto al problema de la relación entre praxis y conocimiento, al ser un problema filosófico central también para Sánchez Vázquez, Schmidt observa: "En el terreno de la praxis concebida se pone de relieve la mala abstracción de un sujeto 'carente de mundo', puramente mental, al igual que la de un mundo 'carente de sujeto', existente en sí. La praxis como realización efectiva enseña lo vacías que son las alternativas determinadas fijamente 'en la teoría del conocimiento' o en algún invariable punto de vista". ${ }^{22}$

Así pues, siguiendo tanto a Sánchez Vázquez como a Alfred Schmidt, puede decirse que en la postura acrítica de la izquierda dogmática, así como de la reformista, se descubre una peculiar combinación de materialismo mecánico e idealismo. Esto no significa que los defensores de esas posiciones lo tengan realmente en claro. Precisamente en la combinación no concebida (o incluso inconsciente) de esas dos tradiciones filosóficas está enterrado el problema teórico. ${ }^{23}$ La aportación de Marx (y así regresamos a la interpretación hecha por Sánchez Vázquez de las Tesis sobre Feuerbach) consistió en confrontar de manera crítica, es decir, con reflexión, las aportaciones epistemológicas del materialismo mecánico con las del idealismo, para así alcanzar el concepto desarrollado de praxis. Schmidt subraya que, para Marx,

[...] dadas las ineludibles tareas históricas de la humanidad, ya no se trata de argumentar, desde principios superiores del ser y del conocimiento (para lo cual poco importa si se les da una interpretación espiritual o material), sino de partir de la "materialidad" - materialidad que es todo, menos ontológica- de las relaciones vitales del hombre, que "son prácticas desde un principio, quiero decir, relaciones fundamentadas por la acción": relaciones de producción y de clase. ${ }^{24}$

${ }^{22}$ A. Schmidt, "Praxis", en op. cit., p. 1115.

${ }^{23}$ Compárese al respecto. "Marx no 'combina' (lo que sería eclecticismo puro) motivos de reflexión de origen idealista y materialista, sino que dirige la idea (matizada de diversas maneras desde Kant hasta Hegel) de que todo lo inmediato es ya mediado, contra su formulación hasta entonces idealista" (A. Schmidt, "Einleitung", en op. cit., p. 11).

${ }^{24}$ Idem. Schmidt cita aquí K. Marx, Notas marginales al Tratado de Economía Política de Adolph Wagner. Trad. de F. Blanco. México, Siglo XXI, 1982, p. 40. Schmidt continúa aquí refiriéndose a Mao: "Éstas reflejan en cada caso no sólo la medida en que la sociedad ha alcanzado un verdadero poder sobre la naturaleza, sino que determinan el qué y el cómo del conocimiento humano, del horizonte general en el que se mueve" (A. Schmidt, "Einleitung", en op. cit., p. 11). 
Hay una diferencia entre la interpretación de la obra de Marx de Sánchez Vázquez y la de Schmidt que queremos mencionar aquí; se expresa claramente en las respectivas investigaciones sobre el concepto de praxis. Mientras el segundo comprende la praxis humana como prioritariamente económica, el primero, en cambio, cuando llega a abordar formas especiales de praxis, menciona en particular a la política y la artística. Esta diferencia va acompañada de la diversa ubicación del centro de gravedad por ambos autores en su lectura de Marx. Mientras Sánchez Vázquez se apoya principalmente en los escritos juveniles de Marx, dándole no mucha importancia a El capital, Alfred Schmidt parte de la observación "de que Marx no se muestra de ninguna manera más filósofo cuando se sirve del tradicional lenguaje académico de los filósofos." Por eso, en su libro acerca del concepto de naturaleza en Marx, advierte de entrada que

[...] tomaremos [i.e. Schmidt] aquí en consideración, en una medida mucho más amplia que la habitual en las interpretaciones filosóficas de Marx, los escritos político-económicos del periodo intermedio y maduro de Marx, ante todo el "Rohentwurf" [Grundrisse (borrador)] de "El capital", que es extraordinariamente importante para comprender la relación existente entre Hegel y Marx, y que hasta ahora casi no ha sido utilizado. ${ }^{25}$

Aunque en su teoría estética, Sánchez Vázquez ciertamente se refiere, en algunas ocasiones, a los escritos político-económicos del Marx intermedio y maduro, sobre todo al Rohentwurf (los Grundrisse) de El capital, ${ }^{26}$ en sus textos sobre la filosofía de la praxis se centra sobre todo en los escritos juveniles de Marx. Esta orientación, sin embargo, no se debe relacionar directamente con el "equivocado intento tantas veces realizado hoy, de reducir el pensamiento propiamente filosófico de Marx a lo dicho en estos textos, particularmente a la antropología de los Manuscritos parisinos". ${ }^{27}$ Ocurre más bien que Sánchez Vázquez comparte esta crítica formulada por Alfred Schmidt en relación con la época de génesis de su libro sobre el concepto de naturaleza:

En estos años, décadas de los cuarentas y cincuentas, el joven Marx ante la mirada sorprendida de los marxistas, se convierte en propiedad casi privada del pensamiento burgués [...], se buscaba desvalorizar al

${ }^{25}$ A. Schmidt, El concepto de naturaleza en Marx, pp. 12-13.

${ }^{26}$ A. Sánchez Vázquez, Las ideas estéticas de Marx. Ensayos de estética marxista. 14a. ed. México, Era, 1986 [1a. ed. 1965], pp. 222-227.

${ }^{27}$ A. Schmidt, El concepto de naturaleza en Marx, p. 12. 
Marx de la madurez en nombre del joven Marx, y, en este sentido, las interpretaciones y críticas se convertían por diversos caminos en armas ideológicas e incluso políticas. La transformación del joven Marx en el verdadero Marx [...] afectaba no sólo a los Manuscritos sino a sus relaciones con la obra de madurez y a su lugar dentro del proceso de formación y constitución del pensamiento de Marx. ${ }^{28}$

Deslindándose con vehemencia del marxismo de Althusser, Sánchez Vázquez insiste en que la obra marxiana es indivisible. Si en sus análisis filosóficos sobre el concepto de praxis se basa principalmente en el Marx joven e intermedio, no lo hace necesariamente porque considere ahí a Marx como 'más filosófico', sino porque el tema de la praxis política y creativa está más en primer plano que en la crítica a la economía política, en la que, ante todo, está en discusión la forma de praxis reproductiva, que sostiene el mundo de los humanos. Esta posición privilegiada que la praxis creativa y sobre todo la político-revolucionaria ocupa en la Filosofía de la praxis de Sánchez Vázquez frente a otras formas de praxis, debe entenderse más por la historia de su propia vida que por reflexiones internas de pura teoría. Si se ocupa de Marx, ello se debe ante todo a su actividad política de la temprana juventud.

El cambio de país, impuesto por motivos políticos, (que también afectó a Sánchez Vázquez) da como resultado una presencia permanente, casi ineludible, de lo político (sobre todo en relación a su país de origen) en la vida cotidiana de los exiliados. Quiéranlo o no, las consecuencias de su propia praxis política desempeñan en la vida de los exiliados un papel determinante y, para el propio ajetreo de la vida cotidiana, pueden ser más imperiosas que las que surgen directamente de la praxis reproductiva. Estas últimas, por el contrario, determinan la vida cotidiana de los individuos que nunca se vieron obligados a cambiar de país por motivos políticos, más que la (propia) praxis política y sus consecuencias. Por eso no constituye un asunto de pura motivación teórica interna, sino procedente de la misma praxis política, el hecho de que Sánchez Vázquez, en el análisis filosófico, se vuelva más hacia la praxis política que hacia la reproductiva. ${ }^{29}$

${ }^{28}$ A. Sánchez Vázquez, Filosofía y economía en el joven Marx. Los manuscritos de 1844. México, Grijalbo, 1982, p. 227.

${ }^{29}$ Brecht ve igualmente una relación directa entre la emigración y la forma de crear la teoría: "La mejor escuela de dialéctica es la emigración. Los dialécticos más agudos son los refugiados. Son refugiados porque se han producido cambios y ellos solamente estudian los cambios. De los menores indicios deducen los máximos acontecimientos, siempre que tengan buen juicio. Cuando triunfan sus adversarios, ellos calculan cuánto ha costado la victoria y tienen buen ojo para las contradicciones" (B. Brecht, op. cit., pp. 91-92). 
Este resultado de la reflexión acerca de por qué Sánchez Vázquez, pese a su insistencia en contra de Althusser sobre la unidad de la obra marxiana, deja fuera, en su Filosofía de la praxis, casi por completo las posteriores contribuciones marxianas, parece encajar armoniosamente, por así decirlo, en el contexto de una reflexión cuyo objeto principal es la relación bilateral entre praxis y conocimiento.

Sin embargo, queda una duda, y es más que de carácter metódico. ¿No se llegó a esta conclusión con demasiada rapidez: de la praxis a la teoría? ¿Acaso no es uno de los resultados importantes de la interpretación de Sánchez Vázquez de la undécima Tesis sobre Feuerbach, cuando formula sobre ella "se trata de transformar sobre la base de una interpretación", ${ }^{30}$ el que esta frase, la más conocida de todas las de Marx, pierde su indiscutible significado si se enuncia con demasiada precipitación? La respuesta encontrada, ¿no reduce la filosofía a un pensamiento que depende demasiado directamente de la vida cotidiana, sólo que es más sistemático? Si bien es desde luego agradable que un texto parezca justificarse a sí mismo con rapidez, se impone la cautela para no hundirse en una banal autoafirmación. De no hacerse así, a la teoría le iría como a la propaganda política, que conoce la verdad sólo como un medio: "[...] la propaganda altera la verdad en cuanto la pone en su boca". ${ }^{31}$

Hay otro lugar donde Sánchez Vázquez entra más de cerca en el Marx de la madurez, y es en su primer libro sobre Las ideas estéticas de Marx. Pero lo peculiar es que, en sus escritos posteriores, prácticamente ya no vuelve a mencionar El capital ni los Grundrisse. ¿Cuáles pueden haber sido los motivos de ese cambio? La argumentación expuesta, que proviene de la historia de su vida, puede desde luego explicar la diferente ubicación del centro de gravedad para Schmidt y Sánchez Vázquez al escoger las formas de praxis investigadas, pero difícilmente ayuda a hacer concebible un cambio teórico más de veinticinco años después del inicio del exilio. Así pues, entremos algo más de cerca en los aspectos teóricos internos de esta problemática. El propio Sánchez Vázquez valora su libro Las ideas estéticas de Marx como la primera expresión de cierta magnitud de su ruptura con el marxismo dogmático. En particular, le interesa cuestionar una relación inmediata de dependencia entre los desarrollos artísticos y los de índole social: "[...] la historia del arte y de la literatura demuestra que los cambios de sensibilidad estética no surgen espontáneamente, y de ahí la persistencia de criterios y valores estéticos que

${ }^{30}$ A. Sánchez Vázquez, Filosofía de la praxis, p. 166.

${ }^{31}$ M. Horkheimer y T. W. Adorno, Dialéctica de la Ilustración. Fragmentos filosóficos. Trad. de J. J. Sánchez. Madrid, Trotta, 1994, p. 300. 
entran en contradicción con los cambios profundos que se operan ya, en otros campos, de la vida humana". ${ }^{32}$

Con esto, se plantea la necesidad de un desarrollo independiente -revolucionario- del arte, incluso en una sociedad que apenas había realizado una revolución, como la de Cuba en los años sesentas del siglo XX. "La nueva sensibilidad, el nuevo público, la nueva actitud estética tiene que ser creada; no es fruto de un proceso espontáneo". ${ }^{33}$

Terminamos aquí al subrayar la importancia de lo que ha dado Adolfo Sánchez Vázquez al mundo de habla hispana, y al mundo en general, con su interpretación crítica del marxismo que ha sido una de las primeras en toda América Latina y sigue siendo una de las filosofías más importantes de nuestro tiempo.

${ }^{32}$ A. Sánchez Vázquez, Las ideas estéticas de Marx. Ensayos de estética marxista, p. 227.

${ }^{33}$ Idem. 